\title{
A UNIDADE DO FIM COMO CONDIÇÃO DO DISCURSO MORAL E POLITICO
}

Wladimir Barreto Lisboa*

SINTESE - Primeiramente, analisaremos a estrutura da ação humana como apresentada por Aristóteles. Posteriormente, mostraremos como algumas dificuldades enfrentadas pelo filósofo recebem uma nova solução na obra de Santo Tomás. Esta nova solução poderá ser vista como o divisor entre estes dois filósofos no que concerne a questões morais e políticas.
ABSTRACT - We will first analyse the structure of humam action as presented by Aristotle. Then, we will show how some difficulties faced by the philosopher will receive a new solution in the works of Saint Thomas Aquinas. This new solution could be seen as a dividing position between these philosophers about moral and political questions.

Este trabalho procurará situar as teses de Santo Tomás de Aquino acerca de sua teoria moral e política como estruturalmente paralelas às proposições filosóficas de Aristóteles na Ética a Nicômaco. Todavia, embora as estruturas argumentativas sejam paralelas, Santo Tomás de Aquino, ao deparar-se com uma dificuldade proveniente da caracterização do estatuto do fim último buscado nas ações humanas em Aristóteles, acrescenta algumas teses genuínas que dão conta da aporia. Este pequeno paper restringir-se-á à Ética a Nicômaco e aos comentários que Santo Tomás de Aquino aporta ao tema em seus comentários a esta obra bem como na I.a II.ae, da Suma Teológica.

De início, começaremos com a análise da estrutura da ação humana apresentada por Aristóteles. Posteriormente, mostraremos como algumas das aporias enfrentadas pelo filósofo encontrarão uma nova solução na obra de Santo Tomás. Esta nova solução poderá ser vista como divisora de águas das teorias morais concebidas por estes dois pensadores.

Aristóteles e Santo Tomás de Aquino começam a investigação através da análise das condições da ação humana. O primeiro requisito para que possamos predicar ação a alguém é que este indivíduo aja mediado pela representação de uma intenção de realizar uma transformação no mundo, i.e., ele age porque tem um fim que pretende ver alcançado; e, se temos a intenção de realizar algo, é porque tal nos parece ser um bem.

É mesmo assim que Aristóteles começa a Ética a Nicômaco em 1094 a 1:

Universidade do Vale do Rio dos Sinos - UNISINOS - São Leopoldo, RS.

\begin{tabular}{|l|l|l|l|l|l|}
\hline VERITAS & Porto Alegre & v. 40 & $\mathrm{n}^{2} 159$ & Setembro 1995 & p. 533-538 \\
\hline
\end{tabular}


"Toda arte e toda disciplina científica - e o mesmo da ação e da intenção moral - tendem, aos olhos de todos, em direção a algum bem. Justamente proclamamos que o bem é 'isto em direção ao que todas as coisas tendem'".

Do mesmo modo, Santo Tomás, na resposta do artigo dois da questão um, Primeira Parte da Segunda Parte da Suma Teológica, diz: "Todo agente, por necessidade, atua por um fim". ${ }^{2}$

A introdução de um fim para caracterizar a ação é necessária na medida em que é apenas na sua suposição que podemos interromper uma regressão ao infinito. Ou seja, se sempre fizéssemos uma coisa em vista de uma outra, regrediríamos ao infinito, de tal modo que não poderíamos predicar a alguém ter realizado algo, pois ele estaria sempre em vias de realizá-lo. Assim, para que se interrompa este regresso é necessário que nossa ação tenha a intenção de realizar um fim que é buscado por ele mesmo e em vista do qual realizamos todo o resto. Tal será, portanto, o soberano bem, o fim último buscado por nossas ações:

\footnotetext{
"Se, pois, todos os objetos de nossas ações estão ordenados a um fim que desejamos por ele mesmo - todo o resto não sendo desejado senão por ele - e se nós não escolhemos todas as coisas por outra coisa - iriamos assim ao infinito, de modo que o desejo seria vazio e väo - é evidente que este fim será o bem por excelência, o soberano bem". ${ }^{3}$
}

A partir de 1095 a 12 Aristóteles passa a enfrentar o problema da definição do que seja este fim mais elevado do que todos os outros e que, portanto, é o fim buscado pelos indivíduos.

Aristóteles passa, então, a expor e discutir as opiniões contrárias às suas. Discute-as uma a uma para, após, mostrar suas inconsistências. Logo a seguir, Aristóteles apresenta sua solução.

Quanto ao nome que se dá a este bem supremo, todos estarão de acordo em chamá-lo felicidade - eudamonia. Contudo, quando tratamos de determinar sua natureza, as opiniões são bem diversas. Alguns julgam que felicidade identifica-se com o prazer, outros, com as honras, outros, com a riqueza.

Quanto àqueles que levam a vida do gozo, estes não vivem senão a reboque de suas paixões e, portanto, levam uma vida de animais, uma vez que são incapazes de se submeterem a uma regra de razão e, conforme o objeto lhes cause prazer ou .dor, tal será o fim buscado por suas ações.

Já os que pensam que o bem supremo são as honras, Aristóteles reduz seus argumentos ao absurdo. Com efeito, obter a graça da honra está antes à disposição daqueles que honram do que daqueles que são honrados. Ademais, as pessoas que buscam a honra procuram ser honradas por pessoas de discernimento e conhecidas por sua virtude, o que é uma prova de que nos regozijamos da honra concedida porque concedida por um virtuoso, ou seja, a virtude daquele que honra é vista pelo honrado como um bem ainda mais superior.

1 ARISTOTE. L'Éthique à Nicomaque. Trad. Gauthier et Jolif; T. I, II e II. Publications Universitaires de Louvain, 1958. As traduções portuguesas são minhas, a partir da tradução francesa. Adiante, por questão de comodidade, a citação desta obra apresentará apenas a abreviação E.N. e a paginação standard.

$2 \quad S$. Th. Ia. Iae. q.1, a.2.: "Respondeo dicendum quod omnia agentia necesse est agere propter finem".

3 E.N. 1094 a 18. 
Quanto à riqueza, Aristóteles nos diz que é apenas um bem útil, i.e., um bem que perseguimos em vista de um outro. A riqueza tomada independentemente de seu uso não é nem boa nem má. Antes, são as ações que se executam com a riqueza que são ditas boas ou más.

Podemos, até aqui, traçar um estrito paralelo entre a argumentação aristotélica e tomista na caracterização do fim último da ação humana (concernida, até este ponto, com objetos da anima desejante). As considerações feitas sobre o tema na Lectio V do Livro I, números 55 a 73 do comentário à Ética a Nicômaco são, no essencial, retomadas na Questão II da primeira parte da segunda parte da Suma Teológica, onde Santo Tomás discute em que consiste a felicidade.

Diz Santo Tomás na Questão 2, art. 6 da Ia. Iae. da Suma Teológica, concluindo a partir de uma série de argumentos anteriores:

"Assim, o sentido, que é um poder do corpo, conhece o singular, que é determinado pela matéria, enquanto que o intelecto, que é um poder independente da matéria, conhece $o$ universal, que é abstraido da matéria e contém sob ele um número infinito de singulares. Conseqüentemente, é evidente que o bem que é adequado ao corpo e que causa o prazer corporal por sua apreensão pelos sentidos não é o bem perfeito do homem, mas é muito pequeno enquanto comparado com o bem da alma". 4

Retomando ainda Aristóteles, é em 1097 a 23 que o filósofo finalmente avança sua posição acerca da determinação do fim último de nossas ações:

"Ora, que os fins sejam muitos, isto salta aos olhos. Mas é dentre eles que nós escolhemos outros, por exemplo, a riqueza, as flautas e, em geral, os instrumentos. É, pois, evidente que eles não são todos fins finais. Ora, isto também salta aos olhos, o bem supremo é alguma coisa de final, é ele que será o bem buscado, e se há muitos, será o mais final de todos" ${ }^{5}$

Aristóteles parece estar dizendo, no início desta passagem, que todas as nossas ações estão ordenadas a um fim que será o bem, fim da ação humana e, o que é mais importante, se houver muitos bens, estes serão seu fim. Ou seja, Aristóteles parece estar concedendo que a diversidade dos fins buscada na ação humana está inexoravelmente ligada à diversidade dos interesses dos agentes.

Contudo, este modo de apresentação do problema representa apenas uma estratégia argumentativa. Na passagem imediatamente posterior, Aristóteles afirma que, não obstante a variedade de fins, há apenas um que nós perseguimos sempre por causa dele mesmo e não por outra coisa. Tal fim é mesmo, diz-nos ele, a felicidade:

"Ora, isto que é perseguido por si mesmo, nós o chamamos mais final que isto que é perseguido por causa de uma outra coisa, e isto que não é jamais escolhido por causa de uma outra coisa, nós o dizemos mais final que isto que é escolhido tanto por si quanto por esta outra coisa. Concluindo, nós chamamos final pura e simplesmente: 'Isto que é sempre escolhido por si mesmo e jamais por causa de outra coisa' ${ }^{6}{ }^{6}$

4 S. Th. Ia. Iae., q.2, a.6.: "Et ideo sensus, qui est vis corporalis, cognoscit singulare, quod est determinatum per materiam: intellectus vero, qui est vis a materia absoluta, cognoscit universale, quod est abstractum a materia, et continet sub se infinita singularia. Unde patet quod bonum conveniens corpori, quod per apprehensionem sensus delectationem corporalem causat, non est perfectum bonum hominis, sed est minimum quidam in comparatione ad bonum animae".

6 E.N. 1097 a $30-34$. 
Neste ponto da argumentação de Aristóteles surge uma dificuldade que tem sido constantemente apontada por diversos pensadores, sobretudo contemporaneamente. Eles identificariam no texto da Ética a Nicômaco um, ao menos aparente, non sequitur no argumento. $O$ argumento apresenta-se reunido de modo sucinto no primeiro capítulo de um livro de Peter Geach denominado Logic Matters. Geach assim apresenta o problema:

"A falácia lógica que discutirei aqui é muito fácil de ser vista pelo sentido comum em exemplos simples. Por tudo isto, ela é de grande importância filosófica. Qualquer um pode ver que de 'todo menino ama alguma garota' nós não podemos inferir 'há alguma garota que todo menino ama'; [...] A importância filosófica da falácia é dupla. Primeiro, ela tem sido frequientemente cometida em argumentos famosos de grandes filósofos; era fácil para eles cometê-las, pois em contextos filosóficos não podemos ver por intermédio do senso comum o que pode ser verdadeiro e, deste modo, concluir que a premissa pode ser verdadeira $e$ a conclusão falsa, tal como podemos nos exemplos simples da falácia com a qual eu comecei [...].

"Para começar, então, dou exemplos de nossa falácia a partir de escritos filosóficos:

(i) No começo da Ética a Nicômaco Aristóteles passa de 'Nós não escolhemos toda coisa com o propósito de alguma outra coisa, pois deste modo iriamos ad infinitum e o desejo (oréxis) seria vão e vazio' para 'Há um fim das ações que tornamos um objeto de vontade (boulómetha) que é desejado por ele mesmo, e tudo o mais não sendo buscado senão por ele [...] este seria o bem e o melhor' (1094 a 18-22). É claro que ele pensa estar autorizado a passar de: "Toda série cujos termos sucessivos estão em uma relação escolhido com o propósito de tem um termo último' para 'Há alguma coisa que é o termo último de toda série cujos termos sucessivos estão em uma relação escolhido com o propósito de' ${ }^{\text {? }}$.

Assim, esta falácia, ao menos aparente, parece repousar sobre uma suposição igualmente inaceitável: por que os homens, ao planejarem suas vidas, se é mesmo que o fazem, dariam um lugar central e privilegiado a um objeto único e desejado?

A indicação de uma possivel solução a esta aporia é encontrada, creio, em um artigo de Hardie, "The final good in Aristotle's Ethics". ${ }^{8}$ Hardie aponta para uma distinção que não parece anacrônica com o texto aristotélico.

Segundo Hardie, dizer que o fim último desejado é a felicidade não implica em qualquer especificação acerca do estatuto determinado deste fim. Aristóteles parece mesmo afirmar tal ser o caso em 1098 a 20-22:

\footnotetext{
"[...] se, pois, é assim, o bem do homem será uma atividade da alma segundo a virtude, e se há muitas virtudes, segundo a melhor e a mais acabada". ${ }^{9}$
}

Que o fim último seja a felicidade está já estabelecido. Agora, é mesmo óbvio que diferentes pessoas terão diferentes apreciações acerca do modo de atingir-se a felicidade. Na passagem da Ética recém citada, Aristóteles acrescenta: "em uma vida acabada". Isto é, é apenas o conjunto das ações da vida que podem conferir felicidade ao homem. Há um bem determinante de todas as ações, um bem que é buscado por ele mesmo. Alcançá-lo é mesmo o resultado da consecução de um projeto de vida. Entretanto, diferentes pessoas terão uma diferente apreensão do conjunto de ações necessárias para advirmos felizes. $O$ bem detërminante - que Hardie diferencia dos bens denominados inclusivos - aquele que dirige e orienta 0

7 GEACH, P. T. Logic Matters. Oxford, Basil Blackwell, 1981.

8 HARDIE, W. F. R. In: Aristotle, a collection of critical essays, editado por J. M. E. Moravcsik, London, 1968.

9 E.N. 1098 a $20-22$. 
conjunto das ações é, sem dúvida, a felicidade. Todavia, o homem sábio, diante das vicissitudes das ações humanas, priorizará fins que não necessariamente serão priorizxados por outros homens sábiyos. Não há, pxortanto, que se falar em falácia em Aristóteles, já que a impossibilidade de uma ciência do bem que satisfaça os requisitos do saber científico tal como caracterizado nos Segundos Analíticos em 71 b 8, impossibilita, simultaneamente, uma determinação material do que seja a felicidade.

Vejamos, agora, como isto se passa com Santo Tomás de Aquino. Se relacionarmos suas considerações éticas com o paradoxo antes proposto, teríamos, talvez, uma tendência inicial de considerarmos a aporia insolúvel.

Em inúmeras passagens da Primeira Parte da Segunda Parte da Suma Teológica, Santo Tomás afirma que a felicidade humana nesta vida é uma felicidade imperfeita, que a felicidade perfeita apenas é alcançada na outra vida. Nesta vida os homens podem conhecer que Deus existe e podem apenas alcançar uma noção imperfeita e analógica da natureza divina. Apenas na outra vida pode o homem conhecer Deus como ele realmente é.

Na resposta ao artigo 5 da questão quatro da parte acima mencionada, é dito: "A felicidade é dupla: uma é imperfeita e é tida nesta vida; a outra é perfeita e consiste na visão de Deus". Já na questão quatro Santo Tomás havia dito que bens como, por exemplo, a amizade, contribuem para a consecução da felicidade perfeita, embora nenhum bem, salvo Deus, seja necessário para a felicidade.

Feitas, portanto, estas considerações, somos levados a concluir que há um fim último que propociona a plena felicidade, i.e., Deus. A felicidade temporal ou imperfeita tal como alcançada nesta vida é ordenada a uma felicidade perfeita que é alcançável apenas na próxima vida e consiste principalmente na visão de Deus.

Santo Tomás de Aquino, entretanto, como Aristóteles, tampouco, comete a falácia apontada por Peter Geach. Santo Tomás claramente aponta para duas séries distintas de fins que podem ou não confluir. É certo que todo homem tem um único fim natural, i.e., Deus, assim como é igualmente certo que todas as ações humanas têm um fim, a saber, a felicidade, não obstante possa haver uma diversidade na avaliação do modo de persegui-la.

Assim, todo homem tem um único fim natural, bem como todas as ações humanas têm um fim. Agora, quando as ações humanas convergem para o fim natural, então ambas as séries concorrem para um único fim, a felicidade perfeita, a visão de Deus.

O artigo oitavo da questão cinco, Primeira parte da Segunda parte, intitulado "Se todo homem deseja a felicidade", resume bem o ponto:

"A felicidade pode ser considerada de dois modos: primeiro, de acordo com a noção geral de felicidade; e, deste modo, todo homem deseja a felicidade. Pois a noção geral de felicidade consiste no bem perfeito, como estabelecido acima (a.3.4). Mas, uma vez que o bem é objeto da vontade, o bem perfeito de um homem é aquele que satisfaz inteiramente sua vontade. Conseqüentemente, desejar a felicidade não é mais do que desejar isto que se quer para se estar satisfeito. $\mathrm{E}$ isto todos desejam. De outro modo, podemos falar da felicidade de acordo com sua noção especial, como nisto em que consiste a felicidade. Sob esta conside- 
ração, nem todos conhecem a felicidade, pois eles não sabem em que coisa a noção geral de felicidade é encontrada. Conseqüentemente, neste aspecto, nem todos a desejam". ${ }^{10}$

Santo Tomás de Aquino, portanto, ao distinguir as duas séries, não produz 0 non sequitur de passar da afirmação de que "toda relação 'escolhido com o propósito de' deve ter um termo último" para a afirmação segundo a qual "Há um termo último para o qual converge toda série sucessiva de relação 'escolhido com o propósito de'"'.

A manter-se a aporia, teríamos a imposição do discurso cético no âmbito moral e político, pois, então, não seria mais possivel, mantido o paradoxo, falar-se em comunidade de fins no âmbito da civitas ou mesmo de ciência arquitetônica na coordenação dos fins dos indivíduos. A resolução da aporia mostra-se, assim, prolegômeno a um discurso filosófico acerca do ético e do político e, por via de conseqüência, condição de fundação de todo direito natural.

10 S. Th. Ia. Ilae., q.5, a.8.: "Respondeo dicendum quod beatituto dupliciter potest considerari. Uno modo, secundum communem rationem beatitudinis. Et sic necesse est quod omnis homo beatitudinem velit. Ratio autem beatitudinem velit. Ratio autem beatitudinis communis est ut sit bonum perfectum, sicut dictum est (a.34). Cum autem bonum sit obiectum voluntatis, perfectum bonum est alicuius, quod totaliter eius voluntati satisfacit. Unde appetere beatitudinem nihil aliud est quam appetere ut voluntas satietur. Quod quilibet vult. Alio modo possumus loqui de beatitudine secundum specialem rationem, quantum ad id in quo beatitudo consistit. Et sic non omnes cognoscunt beatitudinem: quia nesciunt cui rei communis ratio beatitudinis conveniat. Et per consequens, quantum ad hoc, non omnes eam volunt". 